\title{
Memória e envelhecimento: narrativas sobre questões de gênero e do mundo do trabalho
}

\author{
Ana júlia Rodrigues do Nascimento \\ Mestre em Sociologia \\ Professora da Fundação Educacional de Anicuns \\ anajuliaufg@yahoo.com.br
}

Francisco Chagas Evangelista Rabêlo

Doutor em Sociologia

Professor da UFC

chagasrabelo@uol.com.br

\begin{abstract}
Resumo Esse artigo tem por objetivo interpretar as narrativas dos idosos sobre o mundo do trabalho, sobretudo, com base em discussões teóricas que se têm feito sobre envelhecimento, gênero, trabalho e memória. Problematizaremos o papel assumido pela aposentadoria, visto que em algumas falas, esta é apontada como uma das causas da manutenção o idoso no mercado de consumo. Mostraremos o que pensam os idosos que ainda trabalham, os que não conseguem fazê-lo por motivos de saúde, os que conseguiram-se se aposentar, os que ainda não conseguiram, sobre o valor da aposentadoria, quais as outras fontes de renda, qual o papel da família nessa relação, fazendo um contraponto com o trabalho rural, visto que os idosos de hoje são frutos de coortes de 1920, 1930 e 1940, e este tipo de trabalho era muito comum. É importante, dentro deste cenário, pontuar o fenômeno da feminização do envelhecimento, visto que o público idoso é formado majoritariamente por mulheres, e que fatores como a viuvez e o divórcio proporcionam um envelhecer sem a presença de uma companhia, isso culmina numa movimentação: a busca de atividades que promovam sociabilidade, renda e a busca de novos parceiros. Com base em dados obtidos, vão se delineando também as diferenças entre ser homem e ser mulher e as implicações que delas decorrem. Fator importante e que também pontuamos, trata-se de mostrar que, com o fenômeno do envelhecimento populacional, toda a estrutura social se altera: as relações com indivíduos de outras faixas etárias; a maneira de lidar com os novos desenhos de família; o papel da previdência social e das políticas públicas, enfim, as instituições e os indivíduos mudam suas maneiras de agir, assumem novos papéis na dinâmica da vida social.
\end{abstract}

Palavras-chave: envelhecimento; memória; gênero; trabalho.

\section{Introdução}

A s investigações a respeito do modo de vida das pessoas idosas A têm privilegiado a utilização da memória como expressão de suas vivências e aspirações. Mais do que mostrar o caráter seletivo dos dados fornecidos pela memória, este texto pretende revelar, por via da interpretação das entrevistas feitas com idosos de idades variadas, homens e mulheres, de condições socioeconômicas diversas, que o discurso que toma como base a memória é condicionado, como todo discurso, pelas contradições inerentes à prática social mais ampla e, especificamente, desse segmento populacional. 
Os eixos selecionados (gênero e mundo do trabalho) para esta apresentação foram os que, de imediato, evidenciaram-se durante a pesquisa de campo e nas discussões que, por força dos deveres acadêmicos ${ }^{1}$, fomos incitados a compartilhar com colegas, orientador e examinadores, estes por ocasião do exame de qualificação.

As contradições foram se revelando, uma vez que os entrevistados discorriam sobre suas experiências passadas e atuais e, sem dúvida, a questão de gênero se impõe seja pela feminização desse segmento seja pelos novos papéis que as mulheres idosas passam a experimentar como agentes dessa configuração social.

O mundo do trabalho, por sua vez, permanece como um referencial de integração social, além, é claro, de estratégia de sobrevivência, negativo (opressor) ou positivo (criador de sentido), cedendo espaço para o lazer, para o consumo não apenas pelas injunções da faixa etária em que esses indivíduos se encontram, mas também pela dinâmica da sociedade contemporânea.

Esses eixos vão se ramificando, por força da própria experiência cotidiana dos idosos, em outros tantos itens como cidadania, políticas públicas, novas forma de sociabilidade etc., cujo tratamento exigiu o recorte ora oportuno ora artificial, anda que justificado pela forma de comunicação.

\section{Panorama do envelhecimento populacional no mundo, no Brasil e em Goiás}

A questão do envelhecimento populacional no Brasil e no mundo é um fato que vem sendo discutido e problematizado dentro das Ciências Sociais e fora delas. É uma questão de ordem pública que passou a fazer parte do cotidiano de indivíduos e países inteiros. $\mathrm{Me}-$ diante tal fenômeno, a produção em Ciências Sociais sobre o tema em questão vem aumentando consideravelmente, bem como a correlação do fator envelhecimento com outros temas relevantes dessas ciências, como modernidade, sociabilidade, conflitos, espaços sociais de convivência, violência, questões de gênero, raça, classe social, mundo do trabalho, enfim, há uma gama de conexões entre os referidos temas. A literatura sobre a questão do idoso também não é pequena, considerando o volume de livros e artigos que circulam quer esfera nacional quer internacional (Debert, 2004).

O século XX foi marcado por expressivas mudanças sociodemográficas na população brasileira. Entretanto, a grande alteração notada nas últimas duas décadas, trata-se do declínio da fecundidade e do au- mento do número de idosos. Esses dois componentes passam a ser grandemente enfatizados para explicar as alterações na dinâmica populacional brasileira. O Brasil está se tornando um país de idosos. De acordo com o Censo de 1991, realizado pelo IBGE, a população de 60 anos ou mais de idade, no Brasil era de 10.722.705 de idosos. Já o Censo 2000 registrou que esse público chegou a 14.536.023 de pessoas. Estes dados indicam que o número de idosos aumentou em quase quatro milhões em uma década.

Desse modo, podemos afirmar que o Brasil vem apresentando, nos últimos anos, uma mudança em sua composição populacional. Segundo a Organização Mundial de Saúde (OMS), até o ano de 2025, a população idosa no Brasil crescerá 16 vezes, contra cinco vezes da população total. Isso classifica o país como a sexta população do mundo em idosos, correspondendo a mais de 32 milhões de pessoas com 60 anos ou mais de idade (Esteves, 1998). Sendo assim, não há mais sentido falar que o Brasil é um país de jovens. De acordo com Berquó (2000, p. 13): “O crescimento da população idosa torna-se cada vez mais relevante porque ele já supera aquele da população total”.

Em 1900, a expectativa de vida no Brasil não ultrapassava os 33,7 anos; em 1940 alcançou 39 anos; em 1950 chegou a 43,2 anos; em 1960 já era 55,9 anos; entre as décadas de 1960 e 1980 alcançou os 63,4 anos. Atualmente, a expectativa de vida no Brasil é de 68 anos e as projeções para 2025 é que seja de 80 anos.

$\mathrm{O}$ último Censo do IBGE registrou em Goiânia uma população de 1.093.007 de indivíduos. Desses, 76.184 consistem de pessoas de 60 anos ou mais, o que corresponde acerca de $8 \%$ da população (IBGE, 2000). A mesma fonte aponta que, em Goiânia, houve um expressivo aumento do número de mulheres com mais de 60 anos responsáveis pelo domicílio, o percentual de $38 \%$, em 1991, subiu para 57\% em 2000. Em contrapartida, o número de homens com mais de 60 anos que são responsáveis pelo domicílio diminuiu de 62\%, em 1991, para 43\%, em 2000.

É fato que o número de pessoas idosas cresceu expressivamente, em proporções mundiais, nacionais e regionais. Por razões de organização institucional, tem-se que determinar quem é idoso. Documentos que resultam de estudos e debates sobre a questão, assim como as leis que, ultimamente, são formuladas tendo em vista a população idosa, o Instituto Brasileiro de Geografia e Estatística (IBGE) e a previdência social definem por idoso o indivíduo com 60 ou mais anos. A legislação garante a proteção e inclusão social desse grupo no Brasil, e expressa este conhecimento mediante algumas resoluções: Lei Orgânica de Assistência Social (Lei n. 8.742, de 7 de dezembro de 1993); Política Nacional do Idoso (Lei n. 8.842, de 4 de janeiro de 

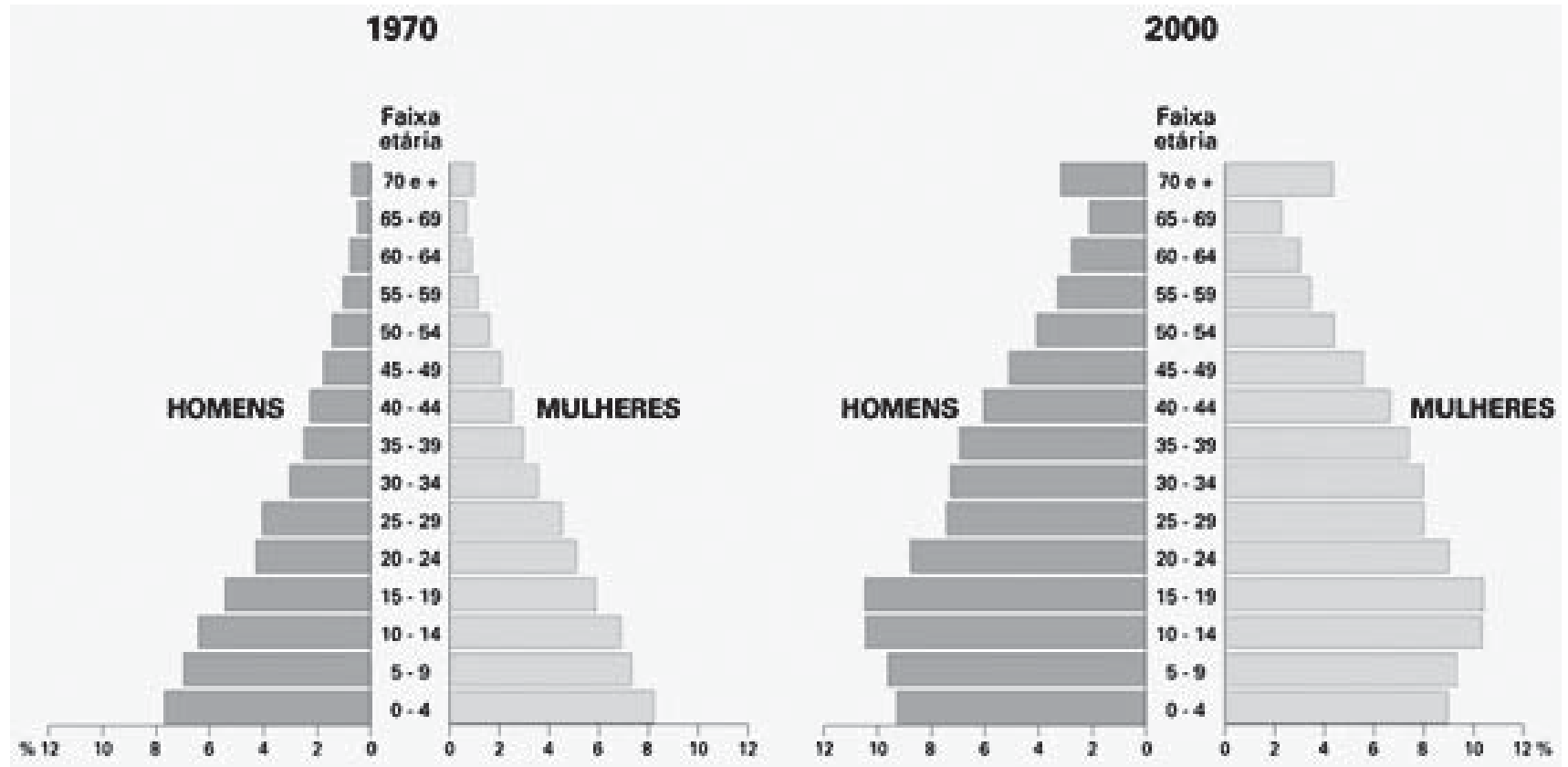

Figura 1: Pirâmide Etária da População Brasileira dos anos de 1970 e 2000

1994) e regulamentada (Decreto n. 1.948, de 3 de julho de 1996); Estatuto do Idoso (Lei n. 10.741, de $1^{\circ}$ de outubro de 2003).

A pirâmide etária (Figura 1), que representa a estrutura populacional, que outrora possuía uma base larga, conseqüência de uma fecundidade elevada, passa a assumir um desenho diferente com o aumento da expectativa de vida da população brasileira a partir da década de 1980. As quedas nas taxas de fecundidade e de mortalidade são as responsáveis por tamanhas mudanças. No tocante à fecundidade, estudos demográficos mostram que as mulheres têm a cada dia um número menor de filhos. A taxa de fecundidade vem caindo significativamente, passando de 6,2 filhos nos anos 1950 para 2,1 filhos por mulher na atualidade (2000), número este considerado mínimo para que uma população possa ser reposta. A população aumenta sua expectativa de vida (melhorias e avanços na medicina etc.) e diminui consideravelmente o número de nascimentos, esta seria a explicação para entender o comportamento do envelhecimento hoje no Brasil. Vale mais uma vez ressaltar que o grupo etário de 60 anos e mais é o que mais cresce comparativamente aos demais grupos.

\section{Na parede da memória: narrativas sobre envelhecimento, gênero e trabalho}

Extraídas da pesquisa de campo desenvolvida para elaboração da dissertação de mestrado em sociologia, as narrativas dos idosos permitem-nos tecer algumas considerações importantes sobre memória, gênero e trabalho.
Barros (2004) afirma que examinar o envelhecimento e a velhice é o mesmo que tratar do tema básico que a antropologia aborda desde o século XIX: a correlação entre as particularidades de contextos sociais distintos, e a generalidade da vida social. Então, estudar a velhice é tratar de representações sociais que os indivíduos adquirem ao longo de suas vidas. O que a autora chama a atenção e deve ser enfatizado, tratase das mudanças no tocante à autonomia do indivíduo em relação ao grupo. Historicamente, sabemos que o grupo (o clã, a linhagem, a aldeia ou a família) sempre predominava sobre as decisões individuais. Conceber indivíduo ancorado na percepção de si mesmo como ser singular é dar visibilidade as idéias de trajetória de vida, ciclo de vida, projeto de vida e percepção de uma memória individual.

Nos estudos sobre idosos, dar visão à memória individual é importante para não homogeneizar um grupo tão heterogêneo. Com essa discussão entra a noção de tempo e espaço. Resgatando a idéia de Debert, Barros assegura que a individuação dos idosos ocorre a partir do momento em que são responsáveis por um envelhecer mais digno, saudável, seguro e agradável. Para tanto, eles devem se ater a cumprir algumas exigências que vão desde uma boa alimentação, perpassam por cuidados físicos e mentais e vão até questões ligadas a um engajamento com os outros idosos, bem como com as atividades ligadas a uma vida ativa que proporcionam várias formas de convivência.

Debert (1997) afirma que os depoimentos dos idosos brasileiros alertam para os perigos que as generalizações sobre a velhice e insistem na distinção entre os velhos em geral e a experiência pessoal, com uma clara diferenciação de gênero. Para Debert, enquanto as mulheres enfatizam autonomia e a liberdade como valores alcançados na velhice, para os homens é a lucidez que 
lhes garantiria nas idades mais avançadas o conhecimento da realidade social e política em que se encontram.

É importante pontuar que mesmo sendo a vida rural cheia de limitações, percebemos no discurso dos entrevistados, a preocupação em aprender uma profissão, em movimentar-se de alguma maneira, sair do interior e migrar para a cidade na busca de trabalho, de se especializar em algo. Havia também uma preocupação com educação, pois a vida na roça não propiciava um nível de estudo maior, que era buscado na cidade.

Eu sou nascido no ano de 1939, fui criado num determinado tempo, até os 11 anos de idade, na zona rural, depois vim pra cidade, na zona rural chegou o tempo da gente não poder mais estudar, não ter mais escola. A gente veio pra cidade e comecei a estudar e aprender uma profissão pra poder sobreviver né? Então a profissão que eu fui aprender foi a de mecânico, mecânico de automóveis, onde eu trabalhei praticamente a minha vida toda, grande parte da minha vida executando a função de mecânico de automóveis, de veículos e de máquinas [...] (Senhor Joaquim, 68 anos, aposentado, mas ainda em exercício, trabalha como cerimonial).

Percebemos nas narrativas desses entrevistados que a vinda para a cidade propiciou várias oportunidades de trabalho e estudo, bem como crescimento profissional, definição de uma carreira, enfim, culminou na abertura de portas para o mundo do trabalho.

Como eu te falei eu não conheci o meu pai, eu trabalhei de engraxate, jornaleiro, carregador de marmita pra peão em obras, lavador de carro, copeiro, balconista, até servente de pedreiro eu trabalhei, mas a partir de logo que eu estudei, formei passei a trabalhar como um profissional na minha área, eu fui gráfico, trabalhei como gráfico cerca de 6 anos, depois eu comecei a lecionar, trabalhei em outros órgãos do Estado, fiz concurso pra delegado e me aposentei como delegado de polícia (Senhor Márcio, 64 anos, delegado aposentado, mas atua como advogado).

Goldani (1999) também argumenta no mesmo sentido. Para essa autora, homens e mulheres vivem de formas diferentes, portanto, ao envelhecer, também apresentam características diferenciadas. Fatores sociais e genéticos como: gênero, raça, classe social, situação conjugal e cuidados prévios com a saúde, possibilitam aos idosos envelhecimentos específicos. Uma característica importante e que deve ser considerada é que a mulher brasileira não teve, em muitos casos ao longo de sua vida, trabalho remunerado, noutros, essa mulher era trabalhadora doméstica ou fazia parte do mercado informal, deixando de ter garantida a sua aposentado- ria. Ainda deve-se levar em conta o fato de as mulheres receberem salários menores que os homens.

Antigamente quando eu tinha minhas filha pequena eu trabalhava de doméstica, trabalhava de faxineira, eu levava e passava e cuidava dos filhos também e hoje em dia eu cuido de 2 netos, minhas filha tenho 3 e tá tudo casada, e eu crio 2 netos, e faço a mesma coisa, eu trabalho, acho bom trabalhar, eu sou faccionista, eu criei minhas filhas assim, lavando e passando e fazendo de tudo um pouco, fiz vários cursos também, quero ver se faço mais e nunca vou parar (Senhora Odete, 60 anos, ainda trabalha como costureira).

Debert aponta que, classificar os indivíduos por períodos etários, é algo importante em diferentes sociedades, pois identifica as diferentes formas de sociabilidade dos indivíduos nos contextos sociais distintos. Os estudos contemporâneos permitem novos recortes de pesquisa e as categorias idade e gênero passam a fazer parte dos mesmos, a diferenciação por idade é também uma questão de organização social. A autora formulou a expressão nos cursos da vida, que serve para caracterizar etapas mediadoras entre a idade adulta e a velhice, tais como a meia-idade, a terceira idade e a aposentadoria ativa. Essas fases são características das sociedades modernas e geram demandas, atores políticos e mercados de consumo específicos.

Para Debert (2000, p. 301), o termo terceira idade, muito utilizado por estudiosos e pela mídia, tem para ela um sentido diferenciado. Diferente da visão depreciativa que adquiriu ao passar dos anos, terceira idade, para essa autora, tem muito mais a ver com juventude que com velhice. De acordo com essa autora, consideramos que, abordar a questão da terceira idade é engendrar diversos discursos, até mesmo aquele reproduzido pela mídia, e trabalhar com a questão dos novos espaços de sociabilidade. O grande avanço nessas análises é pontuar que a idade não é definidora de comportamentos e estilos de vida. Assim, tanto a mídia quanto os grupos que desenvolvem estratégias de sociabilidade ditam uma série de condições como técnicas corporais, hábitos saudáveis, como alimentação e atividades físicas, lugares para o lúdico, a dança, o turismo, as universidades, enfim, estabelecem um novo código para aqueles que não querem se comportar como velhos, apesar dos anos de idade.

Para Bosi (1994), por meio da memória, os ve1 hos ${ }^{2}$ passam horas e horas falando de suas lembranças. Para ela, seria necessário um escutador infinito, já que lembrança puxa lembrança e algumas falas foram realizadas fora do momento da entrevista, em conversas informais, durante o cafezinho, no jardim, no portão, enfim salienta que ao serem instigados para falar sobre 
passado os indivíduos buscam mais e mais lembranças em suas memórias.

De acordo com Thompson (1992), por meio da história e da memória, as pessoas comuns costumam compreender as revoluções e mudanças por que passam em suas próprias vidas: guerras, transformações sociais e mudanças tecnológicas.

Teríamos que começar falando lá da roça, eu considero que Deus encheu os nossos ancestrais de sabedoria, muito embora não tenha nada de intelectual. Uma natureza com muito sábio, muita pessoa que estuda astrologia mas não tem a vivência e a luz que eles têm. Agora ela é sofrida, mas a gente recebe muita graça pra encher a casa de fartura. Tivemos momentos difíceis, não sei se seus pais sofreram com isso. Nos anos $40 \mathrm{e}$ 50 foi criada a lei do usucapião com a ajuda da pastoral da terra, pela Igreja Católica. Então naquela época, ela achou que iria beneficiar quem morasse em terra dos outros, quem vivesse numa terra há mais de quinze anos, ele teria, automaticamente, pela força da lei, direito instituído sobre a propriedade. Então, a partir daí, nós começamos a ser perseguidos, foi tirando de nós toda condição de produzir, foi um sofrimento terrível que eu acho que na época todos nós passávamos ou passamos. Não achávamos lugar pra morar, porque ninguém queria dar agregação pra gente e o fazendeiro começou a tirar de nós a liberdade de produzir, cortou o engenho que a gente moía a cana e fazia aquela fartura, não sei se você conhece, rapadura, doce, aquela coisa linda que fica impregnado na mente. Tirou essa liberdade, desativou o engenho, depois nos proibiu de criar animais, galinha, porco, essas coisas. E assim foi diminuindo nossas condições de sobrevivência. Não havia mais condição para plantar nem produzir. A minha ida pra cidade foi quando tive 9 anos de idade por uma briga interna com um fazendeiro que queria pagar um preço muito baixo pela produção... (Senhor Célio 65 anos, ainda em exercício, comerciante).

Bosi resgata Walter Benjamin, pontuando o papel que assume o narrador. Segundo Benjamin o narrador conta o que ele extrai da experiência - sua própria ou aquela contada por outros. E, de volta, ele a torna experiência daqueles que ouvem a sua história. Resgata também o trabalho de Henri Bergson, ao afirmar que, na realidade, não existe percepção que não esteja impregnada de lembranças.

Parece-nos então que a memória surge como um instrumento eficaz para fazer história, fazer ciência, colocar os indivíduos em contato com sua vida passada, resgatar idéias, ideais, valores, tudo porque Bosi defende a tese que as histórias dos personagens que compõem sua obra mostram sua função social exercida durante a vida, e que estas, fazem parte da memória dos velhos. A memória, na velhice, é uma construção de pessoas agora envelhecidas que já trabalharam.
Assim, é importante resgatar essas memórias, pontuando o atual mundo do trabalho e suas especificidades. A discussão se alonga se fizermos o recorte de gênero, classe social, idade mais ou menos avançada, vida urbana ou rural; enfim, as falas elucidam os exemplos de como os idosos lidaram com as especificidades do mundo do trabalho:

Na roça num tinha nada. Num te falando o que que é roça. Na roça só tinha aqueles serviço grosseiro de roça... Mas a gente passa. Agora quando eu cheguei nessa cidade aqui de Goiânia foi que eu melhorei muito. E que quando meu marido morreu eu fiquei assim num barracãozinho muito ruim. Muito ruim, ele quis muito vender ele e me deixar sem nada e eu num deixei vender e ai depois que ele morreu minha vida consertou muito. Porque ai eu fiquei assim... Eu num ia disperdiçá meu dinheiro e ai eu trabalhava... E ai eu peguei, entrei numa aula de costura, Deus me abençoou muito nessa aula, muito mesmo. Nesse tempo num tinha tanta costura como tem hoje, hoje tem costura pra tudo quanto é coisa naquele tempo num tinha. Aí eu entrei numa aula de costura e nessa aula eu tive muita sorte. Muita mesmo. Achei muito trabalho, eu trabalhava muito. E foi que acabei de criar meus filhos, acabei de arrumar minha casa e depois, e depois quando eu pensei que não... Eu fiz essa casa, eu tenho essa casa aqui. Tenho outra no fundo que mora essa moça e tenho outra que da... Tudo isso com inteligência minha, mais minha cabeça... Poxa uma pessoa de noventa e tantos anos num tem uma cabeça como essa sua não! Eu tenho porque ninguém num me passa pra traz não, eu tenho...E aí como eu tou lhe dizendo como é que é a vida. E nisso eu vou levando... (Dona Aninha, 96 anos, aposentada)

Ao falar sobre sua família, uma entrevistada de 60 anos de idade, aposentada, com renda superior a $\mathrm{R} \$$ $5.000,00$, conta que sua família passou por algumas dificuldades após a morte do pai, que a mãe teve que assumir papéis antes atribuídos somente ao esposo.

Meu pai morreu jovem, com 40 anos incompletos, e mamãe ficou viúva com 38 anos e 9 filhos, a mais velha com 18 e a mais nova 07. Enfrentamos muitas dificuldades, mas à medida do tempo ela teve que trabalhar para sustentar os filhos. Trabalhou em atividades humildes... Engraçado, que ela mudou porque ela era o tipo de mulher assim, o marido é que resolvia todos os problemas. Ela era essencialmente esposa. Esposa, mãe e dona-de-casa. E ela teve que trabalhar, um trabalho humilde e aprendeu a se virar. Aprendeu a andar em Goiânia, aprendeu a resolver problema de banco, a arrumar dinheiro emprestado, e resolver tudo, né? Mas à medida que os filhos foram crescendo, estudando, todos em escola pública, a coisa foi entrando mais ou menos nos eixos (Dona Pérola, 61 anos). 
Fica clara a relação da memória e trabalho, bem como a da memória e gênero, e a de gênero e trabalho, visto que, à mulher, eram reservados alguns postos ou obrigações, como o de ser mãe, esposa e dona de casa. A morte ou o divórcio são fatores de extrema relevância para alterar essa lógica. As mulheres têm que assumir novos papéis, aprender novo ofício, sustentar a si mesma e aos filhos, tomar as rédeas, aprender a tomar decisões, decidir-se por um tipo de atividade que lhe proporcione renda.

Diferentes são os relatos de uma entrevistada com nível de renda alto. Esta possui afazeres cotidianos diferenciados daquelas de baixa renda. Prioriza a leitura em seus momentos de lazer, ajuda parentes mais necessitados, possui capital cultural e, em suas memórias, relembra o ambiente de trabalho onde possuía um cargo público e atuava como advogada.

Antigamente eu trabalhava. Eu comecei a trabalhar com 16 anos e trabalhei ininterruptamente durante 30 anos, até me aposentar. Hoje pra preencher meu tempo é minha atividade de mãe, de dona-de-casa. E lazer é a televisão, leitura, leio muito, tudo que me cai nas mãos e programas assim... Programa popular, programa de nível cultural, de informação, eu gosto muito também (Dona Pérola, 61 anos, advogada aposentada).

Concomitantemente ao fenômeno do envelhecimento, verificamos que os inúmeros desafios trazidos pela modernidade acarretaram transformações importantes e decisivas no mundo do trabalho, como a industrialização e a urbanização, gerando consequiências nas mais diferentes instâncias da vida das populações. Os trabalhadores, que não acompanharam essas mudanças e que não têm como preparar-se para responder às necessidades impostas por esta nova ordem, estão automaticamente desligados e fora do mercado de trabalho. Nesse sentido, as implicações tendem a se avolumar uma vez que este indivíduo é uma mulher e idosa.

Verificamos ao longo das entrevistas que parte dos idosos entrevistados ainda trabalha. Alguns para complementar a aposentadoria que, no geral, é pequena. Outros vêem no trabalho uma maneira para se distrair, fugindo assim da rotina cotidiana. Há aqueles que dizem amar o trabalho, afirmam que querem fazê-lo até a hora da morte. Outros não podem realizá-lo por motivos de saúde. Existem, ainda, idosos que precisam manter o sustento da família e pontuam que mesmo tendo condições físicas limitadas, dado o avanço da idade, ainda precisam trabalhar.

Eu brinco, mas no fundo é uma grande verdade, se Deus me permitir eu quero morrer com a máquina fotográfica pendurada no pescoço, porque realmente eu gosto. Ficar em pé, abaixar, ficar em pé, abaixar, cansa, mas é assim gratificante. Se me perguntarem se quero fotografar, respondo que quero. Vamos fotogra- far 3 por dia? Vamos. Eu gosto, faço porque gosto. Eu vou pra um casamento, pra um aniversário, esqueço do que é cansaço, depois de uma certa hora eu preciso dar uma parada, uma sentada, mas às vezes eu fico 3 horas de pé fotografando e nem vejo o tempo passar (Senhor João, 67 anos, não é aposentado e é fotógrafo).

As situações, acima citadas, permitem-nos concluir que não há como homogeneizar o segmento idoso. Eles têm problemas comuns como indivíduos de outras faixas etárias. As questões econômicas e de gênero são suas maiores preocupações. $O$ fenômeno da feminização da velhice e a situação de precariedade que essas mulheres, em geral, chegam à idade envelhecida, assumindo postos precarizados no mercado de trabalho, já que não tiveram educação, especialização e nem preparo para assumir uma profissão, submetendo-se a subempregos, baixos salários etc.

No entanto, observa-se que os estudos sobre o mercado de trabalho no Brasil têm privilegiado, na maior parte das vezes, uma ou outra instância, ou seja, idade ou sexo, bem como estão mais direcionados para uma lógica de mercado se esquecendo dos impactos sociais que essas transformações têm acarretado.

É importante também considerar que as políticas públicas que buscam atender a população idosa possuem, na grande maioria das vezes, muito mais um caráter assistencialista, deixando de lado questões como as formas de convivência social, o não se sentir útil, as novas configurações de família, de gênero, ou seja, visam, na maioria dos casos, a promoção de festas, bailes, enfim, não há uma preocupação real com os meios de subsistência, obtenção de renda, desses indivíduos.

Constatamos nas narrativas dos idosos entrevistados que fatores como: a herança rural, a migração para as cidades, as transformações no modelo de família, a viuvez, o divórcio, a saída de casa por parte dos filhos, o baixo poder aquisitivo da aposentadoria ou a sua ausência, a solidão e, até mesmo, o fato de não querer ficar parado, sozinho, sentindo-se inútil, sem renda ou querendo ter uma vida mais digna geram a volta para o mercado de trabalho, a permanência no mesmo, e a informalidade entre esse público, visto que muitos não acompanham as mudanças que o mercado de trabalho demanda, preparação acadêmica, especialização, domínio de língua estrangeira, enfim, não há como concorrer de maneira igualitária com pessoas de outras faixas etárias, além das limitações físicas que o corpo mais envelhecido possui, selecionando apenas alguns postos de trabalhos para os idosos.

Percebemos a correlação da questão de gênero com a questão da vinda da área rural. Essas configuram o seguinte cenário: baixo nível de escolaridade, tanto de mulheres quanto dos homens, algumas práticas machistas, mulheres subordinadas que não adquiriram profissão fora do lar. Idosas contam que viam suas mães subordinadas aos maridos, e que percebem que 
nos tempos atuais a mulher adquire certa consciência de gênero, adquirindo autonomia e liberdade.

Porque quando eu conheci meus pais, meu pai falava e minha mãe nada falava. E as pessoas eram assim muito dominadas nessa época, e a pessoa envelhecia ali os dois sem sair, sem andar e sem conversar quase, e eu fui envelhecendo diferente, fui vendo essas coisas e fui envelhecendo diferente, porque eu acabei de falar que eu, está evoluindo e eu vou me evoluindo junto [...].

Mulheres idosas contam que além de vivenciarem nos relacionamentos de seus pais a relação de dependência, isso ocorria também ao lado de seus maridos. sublinham que não se movimentavam, não conheciam pessoas diferentes, não podiam trabalhar e se especializar. Algumas delas chegam a comemorar a liberdade que a viuvez e o divórcio propiciaram.

Na casa do meu pai era muito segura, meu pai não deixava a gente sair, aí eu casei meu marido também era muito ciumento eu não saia, agora que eu to aproveitando né, venho aqui né (na Fumdec ${ }^{3}$ ), uma amiga minha achou eu muito triste em casa e falou pra eu não ficar em casa não, aí eu comecei a freqüentar e entrei na dança (Senhora Dalva, 73 anos, aposentada, vive sozinha, mas freqüenta grupos de idosos, Sesc e Fumdec na busca de novas sociabilidades).

Já os homens afirmam que sentiam a necessidade de sair do campo para uma vida urbana, que o trabalho rural tornava-se cansativo, pouco compensador, que a educação dos filhos começava a entrar em questão, sendo assim, houve um êxodo rural, gerando também, mudanças diversificadas no mundo do trabalho.

Eu achei que o serviço da roça lá tava me judiando muito, tinha que trabalhar na roça lá pra poder por de tudo dentro de casa, então eu vim pra cidade. Eu entrei numa firma lá e a firma me trouxe pra cá e dessa firma, num deu pra me levar de novo pra roça não. (risos) Aí eu fiquei quieto aqui mesmo (Senhor Saulo, 67 anos, aposentado com uma renda mensal de aproximadamente $\mathrm{R} \$ 1.500,00)$.

Meu pai durou pouco tempo, morreu e eu vim pra Goiânia e fui naturalmente criado pela minha mãe aqui em Goiânia. Uma das preocupações da minha mãe era ler, eu tinha que ler, estudar e aprender, mas nem por isso eu deixei de trabalhar, eu comecei trabalhar aos 10 anos e estou trabalhando até hoje, com 64, não parei e descobri que serviço não envelhece nem cansa ninguém, pelo contrário, liberta, o trabalho. Então, a minha infância foi estudando e trabalhando, nunca parei, e nem por isso eu me transformei em marginal, certo? Eu acho que o que transforma a criança em marginal é esse excesso de zelo, ela tem que trabalhar também, participar, ajudar, se entrosar e se comunicar. Eu me dei bem, fiz curso superior, lecionei em faculdades, e continuo disposto, trabalhando 12, 13, 14 horas por dia (Senhor Márcio, 64 anos, aposentado, renda mensal aproximada $\mathrm{R} \$ 15.000,00)$.

São explicações também causais para o aumento do emprego entre as mulheres, a maior flexibilização do mercado de trabalho e a precarização das relações de trabalho, com o aumento da ocupação por conta própria e da informalidade em geral.

Antigamente eu me sustentava de lavação de roupa, lavava e passava, era o meu sustento, e hoje não, de 15 anos pra cá eu assumi a costurar, virei costureira, então é a minha profissão, eu aposentei com essa profissão de costureira Eu gosto de trabalhar, eu acho que não compensa ficar de braço cruzado, ou então ficar de porta em porta, também eu não acho bom... Eu gosto de trabalhar, fui criada trabalhando... (Dona Marta, 65 anos, aposentada, mas ainda no ofício de costureira).

Além do crescimento contínuo do trabalho feminino, identifica-se, também, uma tendência de manutenção do nível elevado de atividades produtivas até idades mais avançadas. Um estudo realizado pelo Instituto de Pesquisa Econômica Aplicada (IPEA) aponta que as taxas de atividade das mulheres em idades intermediárias e mais elevadas são crescentes, ao passo que as das mais jovens são estáveis, observando-se um progressivo amadurecimento da mão-de-obra feminina ocupada (Lavinas, 2001).

Essa mesma autora mostra que, além do crescimento sustentado da taxa de atividade feminina, outra tendência interessante diz respeito ao melhor desempenho das mulheres na disputa por postos de trabalho. De fato, desde meados dos anos 1980, a taxa anual de emprego das mulheres mostra-se mais elevada que a masculina, levando a um forte aumento do sexo feminino entre os ocupados. A absorção da mão-de-obra feminina tem sido, portanto, superior à masculina em todas as fases recentes da economia brasileira.

Um aspecto fundamental que não podemos deixar de citar, ao tratar das questões do envelhecimento populacional, trata-se da aposentadoria. Segundo Guita Debert (2000), esta é uma nova forma de conceber a velhice e analisar um conjunto de transformações que acompanharam o desenvolvimento da sociedade capitalista e levaram à criação de instituições que ten-

3 A Fumdec é o órgão que representa em nível municipal a política de assistência social, portanto, é responsável pela execução do Projeto Conviver - uma parceria do governo federal com instituições municipais da cidade de Goiânia - amparada por leis federais como a Lei Orgânica da Assistência Social e pelo Estatuto do Idoso. Realiza atividades diárias que promovem a sociabilidade de idosos. 
dem a substituir parcialmente a família no tratamento das gerações mais velhas. Há uma nova maneira de se conceber a aposentadoria que deixa de ser associada exclusivamente ao termo inválido e assume um papel de direito conquistado. Porém, mudanças diversas no mundo do trabalho geram relações conflitantes e competitivas entre as faixas etárias, quando o desemprego e o subemprego atingem os jovens.

Simões $(2003$, p. 16) verificou que, ao longo da história, surgem organizações de aposentados querendo acabar com as indiferenças que alegam sofrer:

Foi esse descaso que as novas associações de aposentados passaram a denunciar e a combater, em nome de uma ação reivindicativa ampla, unificada e autônoma em relação às distintas categorias profissionais.

Para esse autor, somente após ter se organizado como uma categoria política e reivindicado seus direitos, os aposentados adquiriram visibilidade e legitimidade social. A aposentadoria é um fator determinante para a retirada do idoso da atividade produtiva. É importante que a posição do idoso no domić́lio seja verificada, pois se este tiver que sustentar a família e se a renda familiar for baixa, certamente este não se retira do mundo do trabalho, buscando formas alternativas de obter um ganho para complementar a aposentadoria que, em sua maioria, é baixa.

Simões (1997, p. 175) relata que a questão da aposentadoria é um problema de "economia moral", isto é: "que remete ao consenso coletivo em torno da definição de práticas legítimas e ilegítimas, fundamentadas numa visão coerente das normas e obrigações sociais". A questão que se extrai dessa afirmação consiste em definir quem pode e deve trabalhar, gerando assim uma espécie de contrato geracional, que deve ser respeitado.

A aposentadoria, atualmente, gera especulação no mercado de consumo. Com o aumento do público idoso, as empresas de crédito, bem como as de bens e serviços, têm um novo alvo: os idosos aposentados. A mídia mostra as facilidades que um idoso tem de conseguir dinheiro emprestado, bem como de financiar viagens, conseguir cartões de crédito, mesmo que esse aposentado tenha uma renda mensal baixa.

Notamos que os idosos entrevistados lidam com tempo de uma maneira bem diversificada. Há diferentes atividades realizadas por esse grupo e a visão de uma velhice pacata, tranqüila, de mulheres fazendo tricô e crochê dentro de casa é substituída por uma vida ativa, dotada da tomada de consciência por parte dos idosos dos direitos adquiridos, das conquistas, de certa autonomia no tocante à família, na busca de

Quadro 1: Atividades Realizadas Cotidianamente Pelos Idosos

\begin{tabular}{|c|c|c|c|c|c|}
\hline $\begin{array}{l}\text { Codinome } \\
\text { Idade }\end{array}$ & $\begin{array}{l}\text { Formas de obtenção de } \\
\text { renda }\end{array}$ & Diversão, lazer & Atividade Física & Descanso & $\begin{array}{l}\text { Manutenção do } \\
\text { bem-estar }\end{array}$ \\
\hline Odete (60) & Costura/ Aposentadoria & Dança, viagens & Dança/Anda de bicicleta & Não declarou & Limpar a casa \\
\hline Pérola (61) & Aposentadoria & Televisão, leitura & Não pratica & Leitura & Televisão, leitura \\
\hline Harminda(64) & $\begin{array}{l}\text { Pensão/ Aluguel de apar- } \\
\text { tamento }\end{array}$ & $\begin{array}{l}\text { Viagens, idas à univer- } \\
\text { sidade }\end{array}$ & Dança, caminhada & Bordado & Televisão \\
\hline Márcio (64) & $\begin{array}{l}\text { Advogado/ Assessor } \\
\text { Político/ Delegado apo- } \\
\text { sentado }\end{array}$ & $\begin{array}{l}\text { Chácara, leitura, pisci- } \\
\text { na, whisky, amigos }\end{array}$ & Caminhada & Piscina, filmes & $\begin{array}{l}\text { Ensinar o filho } \\
\text { fazer tarefas da } \\
\text { escola }\end{array}$ \\
\hline Célio (65) & $\begin{array}{l}\text { Aposentadoria / } \\
\text { Comerciante }\end{array}$ & Não tem & Ginástica & Família & Família \\
\hline Marta (65) & Aposentadoria / Costura & $\begin{array}{l}\text { Viagens para visitar } \\
\text { filhos, igreja }\end{array}$ & Caminhada & Costura & Costura \\
\hline João (67) & Fotógrafo & Passeios, netos & Não pratica & $\begin{array}{l}\text { Jogos no } \\
\text { computador }\end{array}$ & $\begin{array}{l}\text { Pesquisas na inter- } \\
\text { net, leitura }\end{array}$ \\
\hline Saulo (67) & $\begin{array}{l}\text { Bicos/ Casas de aluguel / } \\
\text { Aposentadoria }\end{array}$ & $\begin{array}{l}\text { Folia de reis, estádio } \\
\text { de futebol, truco }\end{array}$ & Não pratica & $\begin{array}{l}\text { Sentar na rua com } \\
\text { os outros idosos }\end{array}$ & $\begin{array}{l}\text { Ficar com a espo- } \\
\text { sa; visitar amigos }\end{array}$ \\
\hline Joaquim (68) & $\begin{array}{l}\text { Cerimonial/ } \\
\text { Aposentadoria }\end{array}$ & $\begin{array}{l}\text { Igreja, música (é } \\
\text { maestro) }\end{array}$ & Não pratica & Igreja, música & $\begin{array}{l}\text { Reunir a família } \\
\text { em casa }\end{array}$ \\
\hline Fernando (72) & Aposentadoria & Igreja & Caminhada (às vezes) & Não declarou & Dormir \\
\hline Dalva (73) & Aposentadoria & Dança, viagens & Dança & Televisão & $\begin{array}{l}\text { Costura ou bor- } \\
\text { dado }\end{array}$ \\
\hline Joamara (75) & Pensão/ Aposentadoria & Viajar, sair, ir ao forró & Dança & Leitura & Leitura, dança \\
\hline Moema (83) & Aposentadoria & Não tem & Não pratica & $\begin{array}{l}\text { Sentar na porta de } \\
\text { casa }\end{array}$ & Dormir \\
\hline Aninha (96) & Pensão & Não tem & Não pratica & Fisioterapia & Dormir \\
\hline
\end{tabular}

Fonte: Pesquisa novos envelhecimentos: um estudo sobre as transformações e rearranjos da modernidade na cidade de Goiânia (2007/08). 
uma vida que contemple escolhas, estas, mesmo que simplesmente passar uma tarde junto a pessoas da mesma idade, que possuem visões parecidas com as suas, programam passeios, viagens, trocam receitas, tanto culinárias quanto experiências de vida, enfim, o envelhecimento não é mais o mesmo de antigamente.

Mesmo assim alguns idosos ainda afirmam que a aposentadoria é pouca:

Os filhos me ajudam, eu recebo ajuda deles, porque mesmo eu tendo aposentadoria tendo mais um trabalho ainda é pouco, é pequeno o salário, então hoje eu tenho uma grande ajuda deles, eles me ajudam. São meus amigos, eles fazem o que pode. Tudo que eu tenho de necessidade que falta eles sempre estão prontinhos a me ajudar (Senhor Joaquim, 68 anos, aposentado, mas ainda em exercício, trabalha como cerimonial e vive com uma renda mensal de $\mathrm{R} \$ 800,00)$.

Para visualização de como os idosos vivem a relação com tempo, montamos um Quadro das atividades cotidianas realizadas por eles, as de lazer, as que proporcionam alguma renda, sociabilidade, atividade física, o momento de descanso, relação com a família e com as outras faixas etárias e atividades que promovam seu bem-estar (Quadro 1).

\section{Conclusão}

Este artigo buscou discutir aspectos relacionados às narrativas dos idosos quanto ao envelhecimento populacional e ao mundo do trabalho, especialmente no que se refere às questões de gênero. A população idosa cresceu consideravelmente nos últimos anos, e as projeções apontam que continuará a ser destaque nas próximas décadas. Os dados também mostraram que as mulheres são a maioria entre a população idosa: o fenômeno conhecido como a feminização da população idosa. Esse fenômeno mostra-nos que as mulheres assumem novos papéis na vida social.

Podemos afirmar que os idosos estão cada vez mais informados sobre seus direitos, buscam novas formas de convivência, saem de casa, procuram instituições que promovem seu bem-estar, se articulam, falam da criação do Estatuto do Idoso, reivindicam em prol de seus interesses, mesmo dentro de casa, fazem com que seu cotidiano seja prazeroso, enfim, estão de alguma maneira tentando lidar com as limitações e possibilidades que a vida num mundo que se transforma num ritmo intenso proporciona. Vemos também que a sociedade passa a pensar os idosos, isso se manifesta por meio da criação de uma legislação e da formulação de políticas públicas voltadas para esse público específico e a admissão do estatuto do idoso. Notamos que a sociedade e a vida pública incorporam em suas agendas cada dia mais esses idosos.

Para além de pensar-se a questão do idoso num recorte assistencialista, de políticas de previdência e inclusão social, a pesquisa sociológica tem mostrado como o envelhecimento passa a fazer parte do cotidiano das pessoas, colocando-as a pensar de maneira diferenciada esse fenômeno e, nessa medida, passa ser objeto de preocupação não apenas da esfera governamental, mas também de todos aqueles que se preocupam em conhecer a dinâmica da vida social, considerando as mudanças que fenômenos de tal envergadura desencadeiam nos padrões de sociabilidade.

As narrativas dos idosos entrevistados revelam fatores como: herança rural, migração para as cidades, transformações no modelo de família, viuvez, divórcio, saída de casa por parte dos filhos, a baixa aposentadoria ou ausência da mesma, a solidão, e até mesmo o fato de não querer ficar parado, sozinho, sentindo-se inútil, sem renda ou querendo ter uma vida mais digna, geram uma movimentação na vida dos idosos. Notamos a volta para o mercado de trabalho, a permanência no mesmo, e a informalidade entre esse público, visto que muitos não acompanham as mudanças que o mercado de trabalho demanda, preparação acadêmica, especialização, língua estrangeira, enfim, não há como concorrer de maneira igualitária com pessoas de outras faixas etárias, além das limitações físicas que o corpo mais envelhecido possui, selecionando apenas alguns postos de trabalhos para os idosos. Assim, nota-se que os idosos muitas vezes vêem-se obrigados a submeter-se a empregos informais, sem garantias trabalhistas.

Percebemos também dentro deste cenário, uma disposição por parte dos próprios idosos para continuar trabalhando, mesmo alcançando aposentadoria.

Podemos afirmar um tipo de envelhecer específico dos dias atuais, em que os idosos possuem muitas características que antes não possuíam como a busca de novas formas de sociabilidades fora do âmbito da família, algumas famílias são formadas exclusivamente por um indivíduo idoso, em alguns casos é a mulher que chefia esse domicílio, tendo que assumir novas responsabilidades, que antes não lhes cabiam, outras tomam conta dos netos, ajudam financeiramente. Há um grupo que realiza viagens, promove encontros semanalmente para atividades físicas, lúdicas, manuais, enfim, há uma movimentação por parte desses idosos nas maneiras de agir.

O mundo do trabalho também percebe várias alterações. Há um crescimento continuado do trabalho feminino, bem como uma tendência de manutenção do nível elevado de atividades produtivas até idades mais avançadas. Com base em um estudo realizado pelo IPEA verificamos um aumento nas taxas de atividade das mulheres em idades intermediárias e mais elevadas, ao passo que nas mais jovens há uma estabilidade, observando-se um progressivo amadurecimento 
da mão-de-obra feminina ocupada.

Todas essas características foram percebidas valendo-se das memórias desses idosos, que relataram as mudanças que eles mesmos perceberam nas relações de gênero, do mundo do trabalho, no tamanho e papel das famílias, nas novas formas de sociabilidades, nas mudanças das grandes cidades e até mesmo as do mercado de consumo, que se volta cada dia mais para esse público.

\title{
Referências
}

BARROS, Myriam Moraes Lins de. Velhice na contemporaneidade. In: PEIXOTO, Clarice Ehlers (Org.). Família e envelhecimento. Editora FGV. Rio de Janeiro, 2004.

BERQUÓ, Elza; BAENINGER, Rosana. Os idosos no Brasil: considerações demográficas. Texto NEPO 37, Campinas, Outubro, 2000.

BOSI, Eclea. Memória \& sociedade: lembrança de velhos. São Paulo: T.A. Editor, 1979.

BRASIL. Lei n. 10.741, de $1^{\circ}$ de outubro de 2003. Estatuto do Idoso. Lex: Boletim Secretaria de Cidadania, Governo de Goiás, dez. 2004.

BRASILIA- DF. Secretaria Nacional de Assistência Social. Politica Nacional de Assistência Social, 2004.

BRASILIA- DF. Lei orgânica da Assistência Social - Loas. MPAS, Secretaria de Estado de Assistência Social, 1999.

DEBERT, Guita. G. A reinvenção da velhice: socialização e processos de reprivatização do envelhecimento. São Paulo. Edusp; FAPESP, 2004.

DEBERT, Guita, G. Terceira idade e solidariedade entre gerações. In: DEBERT, Guita, G; DONNA, M. Goldstein (Orgs.). Políti- cas do corpo e o curso da vida. São Paulo : Editora Sumaré, 2000. DEBERT, Guita. G. (Org.). Antropologia e velhice. Textos Didáticos. n. 13. IFCH/UNICAMP, 1998.

ESTEVES, O. Velhice e envelhecimento. Revista de Serviço Social e Sociedade. Ano XXIV, Cortez, 2003.

GOLDANI, Ana Maria; CAMARANO, Ana Amélia (Org.). Muito além dos 60: os novos idosos brasileiros. Rio de Janeiro: IPEA, 1999.

LAVINAS, Lena. Empregabilidade no Brasil: inflexões de gênero e diferenciais femininos. Textos para Discussão, n. 826. Rio de Janeiro: IPEA, 2001.

SIMÕES, Júlio Assis. A maior categoria do país: O aposentado como ator político. In: MORAES, Myriam M. Lins de. (Org.). Velhice ou Terceira Idade? Rio de Janeiro. Ed. Fundação Getúlio Vargas, 2003.

SIMÕES, Júlio Assis. Solidariedade intergeracional e reforma da providência. Revista Estudos feministas, v. 5 n. 1. IFCH/UFRS, , 1997.

THOMPSON, Paul. A voz do passado: história oral. Rio de Janeiro: Paz e Terra, 1992.

\section{Memory and Ageing: Narratives on Gender's Issues and the Labor World}

\begin{abstract}
This article aims to analyze the elderly's description on the labor world, mostly, coming from the recent theoretical discussions on aging process, gender, labor and memory. We will focus on the role played by retirement, since, in some discourses, it is pointed as one of the reasons for keeping the aged in the consumer market. We will show what the ones who still work think, as well as the ones who cannot make it due to health problems; the ones who managed to retire, the ones who still could not make it. We also focus on retirement values, other sources of income they might have, the role of the family as a counter point to rural work. In this context, it is important to point the feminization phenomenon of the ageing process, since they are made up mostly by women. It also deals woth important factors such as divorce and widowhood which produce an ageing process without the presence of a spouse. This ends up with a movement in the search for activities that promote the sociability, income and the search for new partners. From the data collected, it's possible to visualize the differences between being a man and being a woman and the implications that emerge from them. Another important issue that we indicate is that, in ageing population process, the entire social structure is adjusted interfering in the relationship with people from other age groups; we also show ways to deal with new family designs and the role of social welfare and public policies.
\end{abstract}

Key words: Ageing process; memory; gender; labor.

Data de recebimento do artigo: 30-05-2008

Data de aprovação do artigo: 05-09-2008 